Published online 2015 July 22.

Letter

\title{
Presentation of Intrauterine Device in a Didelphic Uterus
}

\author{
Firoozeh Ahmadi, ${ }^{1, *}$ Hadieh Haghighi, ${ }^{1}$ Shohreh Irani, ${ }^{1,2}$ and Gholam Shahrzad ${ }^{1}$
}

${ }_{1}^{1}$ Department of Reproductive Imaging, Reproductive Biomedicine Research Center, Royan Institute for Reproductive Biomedicine, ACECR, Tehran, Iran

${ }^{2}$ Department of Epidemiology and Reproductive Health, Reproductive Epidemiology Research Center, Royan Institute for Reproductive Biomedicine, ACECR, Tehran, Iran

${ }^{*}$ Corresponding author: Firoozeh Ahmadi, Department of Reproductive Imaging, Reproductive Biomedicine Research Center, Royan Institute for Reproductive Biomedicine, ACECR, Tehran, Iran. Tel: +98-2123562254, E-mail: dr.ahmadi1390@gmail.com, f_ahmadi@royaninstitute.org

Received: July 8, 2012; Revised: January 15, 2013; Accepted: August 11, 2013

Keywords: Intrauterine Devices; Uterine Anomalies; Ultrasonography

\section{Dear Editor,}

Intrauterine devices (IUDs) as convenient, efficient, relatively safe and inexpensive methods are used to provide a reversible and long-term contraception. IUD insertion in an outpatient setting without prior pelvic evaluation by ultrasound is a predisposing factor for unsuitable placement. We present a patient with a didelphic uterus in which IUD was placed without adequate pelvic examination before insertion.

A 25-year-old woman who had a history of three pregnancy losses in weeks 6, 8, and 12 and one intrauterine fetal death (IUFD) in 34 weeks of gestation was referred to our clinic. She complained of dysmenorrhea and had an IUD placed in an outpatient setting without ultrasound evaluation one year ago as a contraceptive method after recurrent miscarriage. She was referred for tubal and uterine assessment by hysterosalpingography (HSG) before intrauterine insemination (IUI).

A standard hysterosalpingogram was performed. After injection of dye through external cervical os, an apparently unicornuate uterus on the left side of the pelvis with the presence of IUD on the right side of the pelvis was observed. The left tube was seen unilaterally which was normal in course and the caliber (Figure $1 \mathrm{~A}$ ). Having suspected a unicornuate uterus in the first image, a detailed gynecologic examination was performed, considering the fact that a true unicornuate uterus should be differentiated from the didelphic and complete septated uterus in HSG. Insertion of acorn tip into one horn is the common technical problem during HSG that leads to misdiagnosis of didelphic and complete septated uterus as a unicornuate uterus.
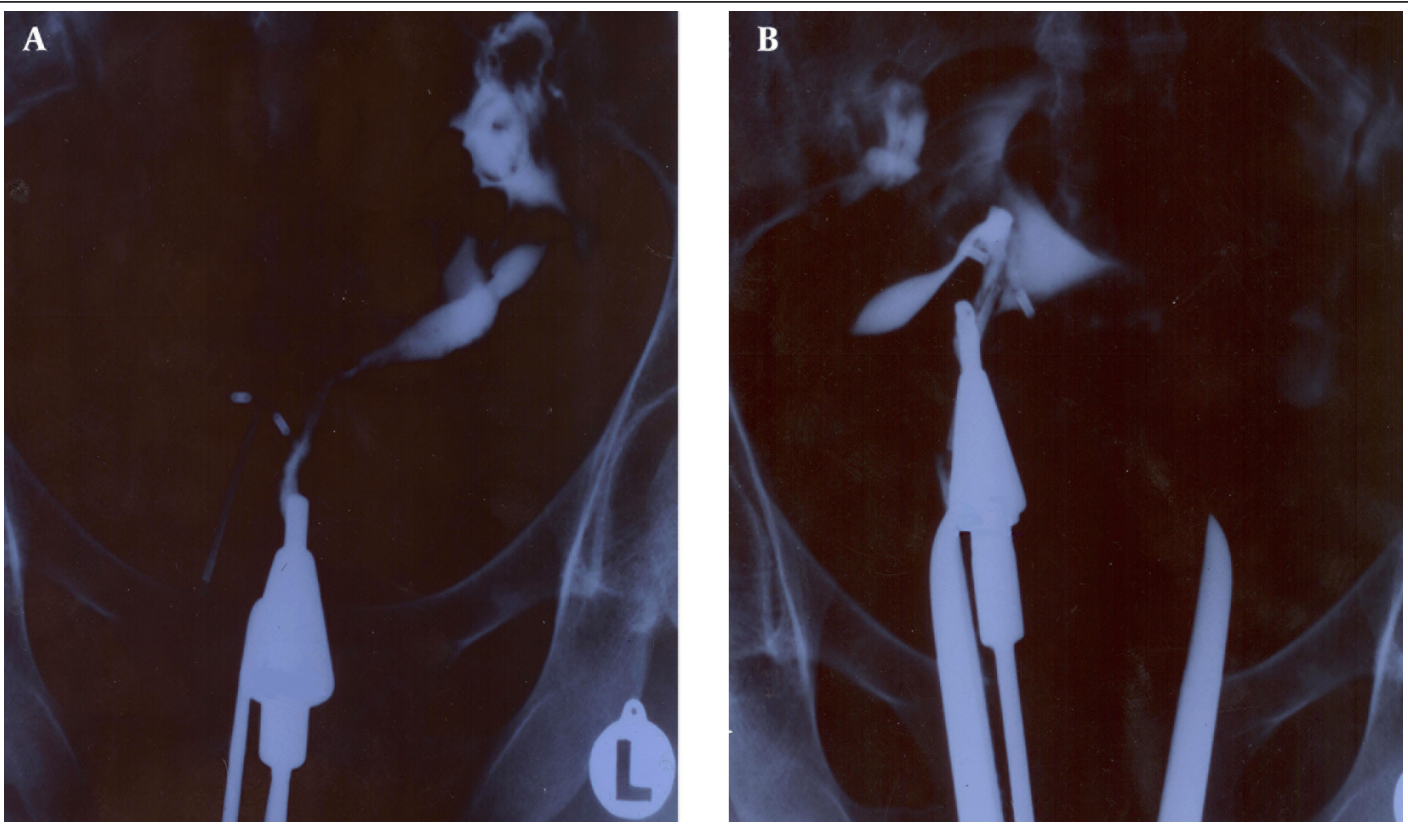

Figure 1. A 25-year-old woman with a history of three pregnancy losses and dysmenorrhea and IUD placement referred for tubal and uterine assessment by hysterosalpingography (HSG) before intrauterine insemination. A, An apparently unicornuate uterus on the left side of the pelvis with a single fallopian tube and an IUD in the right pelvis. B, The right cavity with an IUD is seen in the second HSG image after cannula placement in the second cervical canal.

Copyright (C) 2015, Tehran University of Medical Sciences and Iranian Society of Radiology. This is an open-access article distributed under the terms of the Creative Commons Attribution-NonCommercial 4.0 International License (http://creativecommons.org/licenses/by-nc/4.0/) which permits copy and redistribute the material just in noncommercial usages, provided the original work is properly cited. 


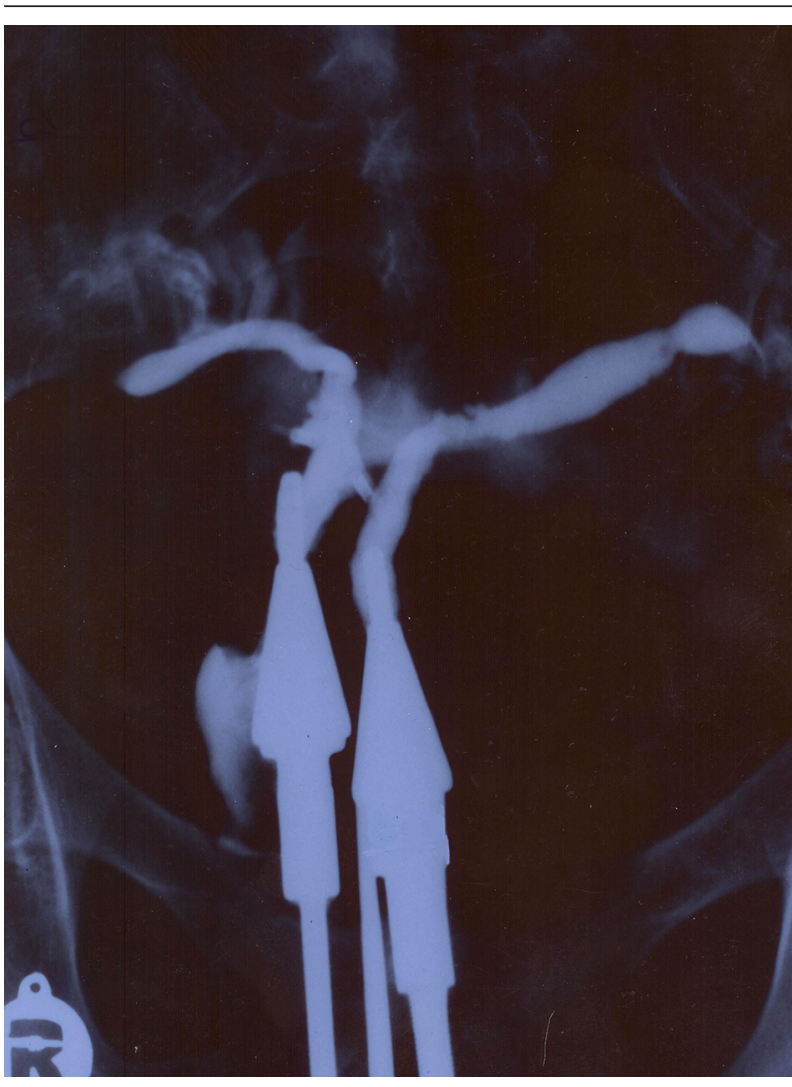

Figure 2. Third image of HSG in the same patient after cannula placement in both cervical canals simultaneously demonstrated a didelphic uterus. Two separate endocervical canals open into separate endometrial cavities.

Gynecologic examination enabled the detection of the second external os. A second image was obtained by dye installation through the second os. On the right a unicornuate uterus with a single fallopian tube and a mislocated IUD fixed at a site lower than normal was detected.
The wings of IUD had penetrated into the uterine walls (Figure 1 B).

A third image was obtained while dye was injected simultaneously through both right and left cervical os. Both cavities were opacified and a contrast was observed bilaterally in the fallopian tubes. Two separate cavities, two cervical os and two fallopian tubes confirmed a didelphic uterus (Figure 2). She was referred to a gynecologist and hysteroscopy was done to remove the IUD.

Didelphic uterus is a rare type of müllerian duct anomalies (MDAs) and the incidence in general population, although not precisely known, ranges from $0.1 \%$ to $3.8 \%$ (1-3).

The most common risks in this case were uterine perforation at the time of IUD placement and also unwanted pregnancy as the IUD was placed into only one side of the cavity. Specific characteristics of the women at the time of insertion such as uterine cavity length, uterine position and unsuspected MDAs have an important role in IUDs failure. Thorough gynecological exam, ultrasound evaluation and proper medical history taking prior to insertion can be helpful in preventing an unsuitable placement.

\section{Acknowledgements}

The authors wish to thank the imaging department staff for their assistance in figure preparation.

\section{References}

1. Al Kadri H, Al-Hunain S, Al Rubaish S, Alamir A, Alfakeeh K. Didelphic uterus and obstructed hemivagina resulting in obstructed hydronephrosis of transplanted kidney. J Pediatr Surg. 2009;44(1):e13-5.

2. Burgis J. Obstructive Mullerian anomalies: case report, diagnosis, and management. Am J Obstet Gynecol. 2001;185(2):338-44.

3. Zurawin RK, Dietrich JE, Heard MJ, Edwards CL. Didelphic uterus and obstructed hemivagina with renal agenesis: case report and review of the literature.J Pediatr Adolesc Gynecol. 2004;17(2):137-41. 